\title{
El Cristo de Jerusalén y Buen Viaje de la Hermandad de los Judíos de Huelva \\ http://dx.doi.org/10.33776/hh.v15i0.5292
}

Rocío Calvo Lazaro rociocalvolazaro@gmail.com

Fecha de recepción: 15/05/2018

Fecha de aceptación: 20/06/2018

\section{RESUMEN}

La hermandad de los Judíos de Huelva, hoy conocida como La Merced, es una de las hermandades más antiguas de la Semana Santa onubense. Actualmente sus imágenes titulares son las más antiguas ya que lograron salvarse de los fastos de la Guerra Civil española. Data del siglo XVIII y se ubica desde su fundación en el templo mercedario, hoy catedral de la ciudad. Sus orígenes se remontan cuando los frailes mercedarios crearon la Venerable Orden Tercera de Servitas e hicieron a la Virgen de los Dolores su titular, comenzando a procesionar el Domingo de Ramos de 1792. La hermandad procesiona en la tarde del Jueves Santo.

El Cristo de Jerusalén y Buen Viaje de la hermandad de los Judíos de Huelva es actualmente la segunda imagen de Cristo más antigua que procesiona en la Semana Santa onubense. Data del siglo XVII. Es de autor desconocido pero posiblemente se encuadra dentro de la escuela gaditano-genovesa por entender que posee ciertas similitudes con imágenes de esta escuela y porque sabemos que fue traída desde Cádiz por los monjes mercedarios. Se ubica desde su ejecución en el templo mercedario.

\section{Palabras clave}

Judíos; Merced; altar; devoción; autoría

\section{Abstract}

The brotherhood of los Judíos from Huelva, now known as La Merced, is one of the most ancient brotherhood in the Holy Week in Huelva. Currently, their sculptures are the most ancient due to they have managed to stay safe from the faustus during the Spanish Civil War. It dates from the 18th century and has been in the temple of la Merced since its creation. The temple has since been converted and is now a cathedral. Its origins go back when the Friars of the Merced created the Venerable Third Order of Servites and they made the Virgin of Dolores their holder, beginning to include it in processions on Palm Sunday in 1792. Nowadays the brotherhood features on the evening of Holy Thursday.

The sculpture of the Christ of Jerusalén y BuenViaje of the brotherhood of los Judíos from Huelva is currently the secondoldest Christ sculpture which features in the Holy Week procession in Huelva. It has managed to stay safe from the faustus during the Spanish Civil War. It dates from the 17 th century. It is by an unknown sculptor butis likely part of the Cadiz-Genovese school for understanding as it has certain similarities with sculptures of this school and because we know it was brought from Cádiz by the Friars of the Merced. The sculpture has been in the temple of la Merced since its creation.

\section{KeY wORDS}

Judíos; Merced; altar; godliness; authorship. 


\section{Pinceladas históricas acerca del origen de la hermandad}

El convento de religiosos de la Merced Descalza se fundó en Huelva en 1605 por iniciativa del XI Conde de Niebla don Manuel Alonso Pérez de Guzmán y su esposa, doña Juana de Sandoval y Rojas, convirtiéndose en el cuarto de la ciudad.

Años después de la fundación del convento mercedario, ya se veneraban en el interior del templo de la Merced, en altares independientes, las imágenes del Santísimo Cristo de las Cadenas y de Nuestra Señora de los Dolores, efigies que siglos después se unirían en una misma hermandad de penitencia.

Los frailes de la Merced se fijaron especialmente en la Virgen de los Dolores, incrementándose la devoción hacia ella, creándose en dicha iglesia la Venerable Orden Tercera (V.O.T.) de Servitas, ${ }^{1}$ cuyo culto estaba especialmente dedicado a los dolores de María en la vida, pasión y muerte de su hijo. ${ }^{2}$

Los frailes mercedarios pidieron las licencias correspondientes a sus superiores para crear la Esclavitud de los Siervos de María, que se estaba fundando en la mayoría de los pueblos de España, y esta fue concedida el 15 de diciembre de 1771 por el Prior General de los Siervos de María para fundarla en la iglesia mercedaria onubense. ${ }^{3}$

Veinte años después de esta fundación se inician las salidas procesionales de la hermandad. El documento que acredita esta primera salida tiene la fecha del 15 de marzo de 1792 y se conserva en el archivo Diocesano de Huelva, fue hallado por el profesor Manuel José de Lara Ródenas; ${ }^{4}$ en él se explicita el acuerdo adoptado por la Junta General de sacar a la Virgen en procesión por Semana Santa, estableciendo como día de salida el Domingo de Ramos. ${ }^{5}$

Tras ser expulsados los padres de la comunidad mercedaria en los procesos de exclaustración decimonónicos y, tras la desamortización y supresión del convento de la Merced en 1835, vino en decadencia total la V.O.T., que ya no venía haciendo su anual estación de penitencia por Semana Santa.

Tras varios años de inexistencia, el 19 de marzo de 1862, el presbítero onubense Francisco de Paula Monís, que había reorganizado ya la hermandad sacramental de San Pedro y fundado nuevas hermandades, reunió a varios hermanos y otras personas y cambió por completo la faz de aquella V.O.T. para que subsistiese, no reorganizándola sino creando la cofradía de penitencia, que vino a desfilar con los mismos hábitos Servitas en homenaje a la comunidad mercedaria.

1 La Orden Servita surgió en Florencia en 1233, donde siete caballeros el Viernes Santo de dicho año deciden crear una fundación, como Orden Terciaria de Siervos de María, para meditar sobre el dolor de María y la pasión de Cristo. El Papa Inocencio IV aprobó sus primeras constituciones en 1242, con tres facciones: dos religiosas y una seglar.

2 Huelva, A.M.H. F.D.H., carpeta 1058.4. Escrito de Diego Díaz Hierro.

3 D. DíazHierro, Historia de la Merced de Huelva, hoy Catedral de su Diócesis, Huelva, 1975, p. 394.

4 M. J. LaraRódenas, "Una nueva procesión de Semana Santa en la Huelva del siglo XVIII. Descubrimiento sobre los orígenes de la Hermandad de los Judíos", El Contraguía, no 4. (1993), p. 20.

5 Huelva, A.D.H, justicia, caja 6. Serie 1 Ordinarios, clase 1, números 114-149, años, 1796-1813.Expediente no 116, pleito, desarrollado en 5 de febrero de 1798 entre la Congregación de Servitas y los Beneficiados de la villa de Huelva. 
Por tanto, la hermandad actual que renunció a seguir siendo V.O.T. fue fundada con la base anterior Servita en 1862, habiéndose aprobado canónicamente sus estatutos en 1864. ${ }^{6}$ Los documentos hallados dan a entender que el Cristo de las Cadenas procesionaba junto a la Virgen de los Dolores desde antes de la citada reorganización.
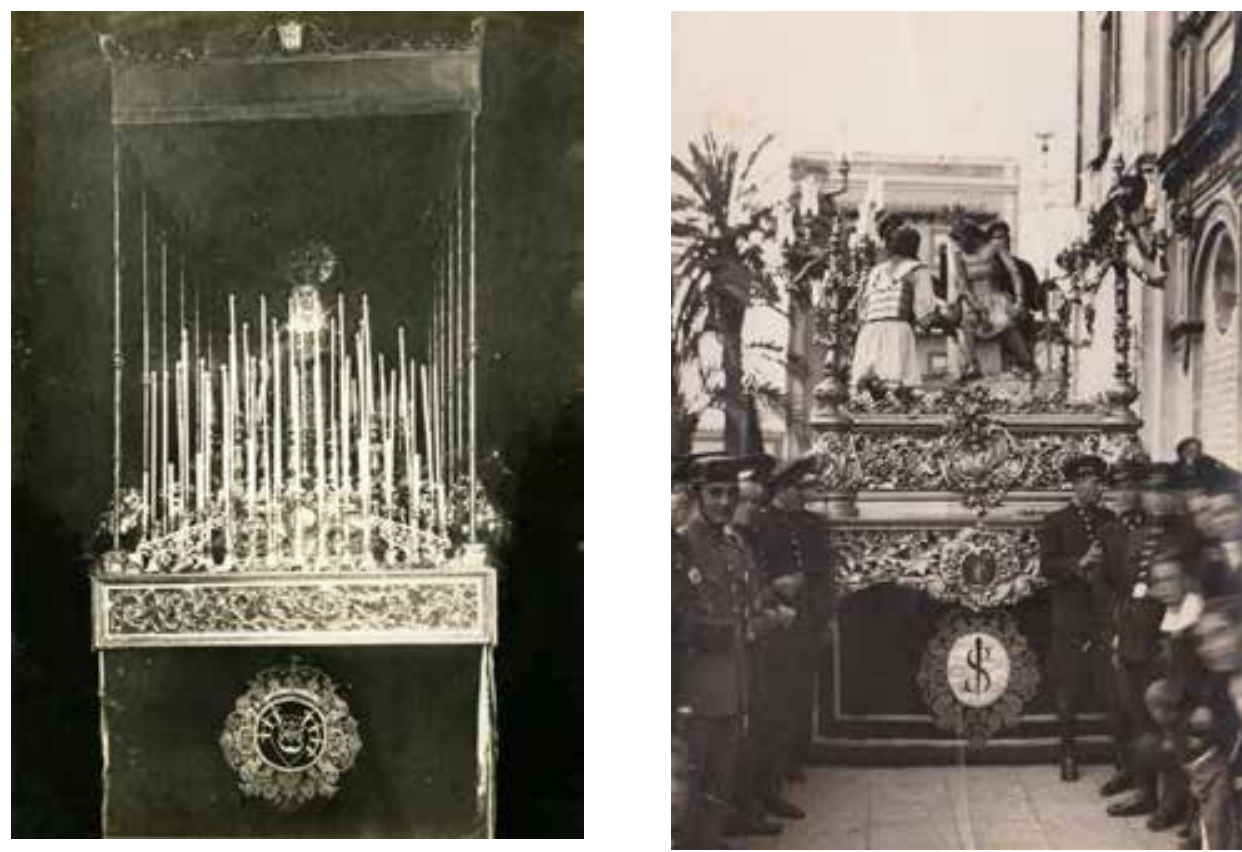

El Cristo de la Cadenas y la Virgen de los Dolores en sus salidas procesionales, principios del siglo XX. Fotografías cedidas por la hermandad de los Judíos

\section{La originaria imagen del Cristo de Jerusalén y Buen Viaje}

Con respecto al origen de la imagen del Cristo de Jerusalén y Buen Viaje de esta hermandad existen dos posibles teorías. La primera de ellas es que la imagen ya se encontraba en la ermita de la Vega Alta cuando se fundó el convento, y la otra defiende que fue traído en la primera mitad del siglo XVII, como el Cristo de las Cadenas, por los padres mercedarios desde su convento del Puerto de Santa María o de Cádiz.

Nosotros nos decantamos por la primera teoría, que también es defendida por Diego Díaz Hierro; es decir, que la imagen ya existía en la ermita de San Roque a la llegada de los religiosos mercedarios, en la víspera del día de Pentecostés del año 1605. En la crónica mercedaria se dice que en la ermita existían dos altares; probablemente uno fuera el de San Roque y el otro el del Crucificado.

"Quedáronse todos en la hermita, donde les trajeron con que hacer colación; y hecha la barrieron y limpiaron, que necesitaba dello porque los dos religiosos que ha- 
bian antes venido concluyeron aquella misma tarde la obra de un coro que hicieron de tablas y otros remiendos y adobios, y con mucho que hubo entonces que entender, no tuvieron lugar de sacar la tierra y astillas que de dicha obra habian resuelto. En esto y en componer dos Altares que alli habia estuvieron hasta media noche y, sin embargo de estar rendidos con lo que caminaron por la mañana y trabajaron desde que alli llegaron hasta entonces, dixeron sus maitines con toda solemnidad".

Por el acta capitular de 7 de enero de 1602 sabemos que la ermita de San Roque recibía también la denominación de ermita de la Cruz.

"...por una enfermedad que ha tenido de que se ha visto apretado, ha prometido un convento en esta villa de frailes Descalzos Agustinos, para que con ayuda de Nuestro Señor se haga en la ermita de la Cruz o San Roque, que es la entrada del lugar". ${ }^{8}$

Existe la hipótesis de que en la ermita de la Cruz o Santa Cruz, situada a la salida de la población hacia el norte y cercana al embarcadero de la ría del Odiel, existiera una imagen de un Cristo crucificado, devoción de los viajeros que emprendían camino hacia los señoríos de Gibraleón y Ayamonte, y hacia el reino de Portugal, y de los marineros que embarcaban a la pesca o a la navegación de cabotaje. Allí se encomendaban todos ellos a San Roque y al Cristo de Jerusalén y Buen Viaje, cuyo último nombre responde a la demanda de protección de quienes tenían que salir a los caminos del reino.

En 1582 se levantó la ermita de San Roque, que probablemente absorbió a la de la Cruz, razón por la que fue conocida como ermita de la Cruz o San Roque. A la nueva edificación debió pasar la imagen del Cristo.

La suposición de que la imagen fuera traída desde Cádiz es defendida por José González Isidoro, quien atribuye el Cristo de Jerusalén y Buen Viaje a la escuela gaditanagenovesa, por los rasgos estilísticos que tiene en común con el Cristo de las Cadenas, especialmente en la dureza de sus anatomías. González Isidoro opina que Jerusalén y Buen Viaje

"conecta con bastantes creaciones analogias existentes en la Babia, todas ellas próximas a la plástica de Joaquin María, el patriarca de los Mayo, a quien se debe el gaditano Cristo de la Piedad, el del Hospital de San Juan de Dios de la propia ciudad, o el más que patético, desgarrador, del Amor; en las Capuchinas de El Puerto de Santa Maria, el que preside la Iglesia Mayor de San Fernando, el también isleño de Vera Cruz e incluso el Calvario de pequeño formato existente en la Palma del Condado, en el Convento de las Hermanas de la Cruz". ${ }^{9}$

7 D. Díaz Hierro, Historia de la Merced de Huelva, hoy Catedral de su Diócesis, Huelva, 1975, p. 55.

8 D. Díaz Hierro, Historia de la Merced de Huelva, hoy Catedral de su Diócesis, Huelva, 1975, p. 132.

9 J. González Isidoro, "Imaginería Barroca de Huelva”, El Dintel 4. (1998), p. 9. 
El historiador Francisco Javier González García también defiende la hipótesis de que esta imagen debe pertenecer a la escuela gaditano-genovesa, atribuyéndola esta vez al escultor Jacome Baccaro y datándola en el siglo XVIII. Compara al crucificado con el Cristo de la Flagelación de Jerez de la Frontera, obra de este escultor. ${ }^{10}$

El profesor Andrés Luque Teruel indica que ambas imágenes cristíferas, Jerusalén y Cadenas, son obras anónimas que pueden vincularse directamente con la escuela gaditano-genovesa, e incluso en el caso del Cristo de Jerusalén y Buen Viaje podría relacionarse con los escultores del Arsenal de la Carraca de San Fernando, en concreto con la obra de Samuel Howe y José Tomás de Sirartegui Saralegüi.

Aunque ciertamente el Señor del Buen Viaje posee ciertas semejanzas con algunas obras de estos escultores, especialmente es reconocible la similitud de la nariz afilada, la imagen que tratamos tiene más crudeza anatómica, además de que estos artistas concentraron su producción artística en la segunda mitad del siglo XVIII, nosotros sin embargo nos decantamos a pensar que es una imagen encuadrable en el siglo XVII.

No obstante, las últimas investigaciones hechas por el profesor Moreno Arana apuntan a la posibilidad de que en realidad se trate de una obra portuguesa. ${ }^{11}$

Por la antigüedad que puede tener esta imagen, si verdaderamente se encontraba en el convento antes de 1605, se descarta la posibilidad de que se trate de una imagen traída desde Cádiz y perteneciente al estilo gaditano-genovés que eclosionó en el siglo XVIII, siendo muy posible su relación con escultores portugueses de finales del siglo XVI.

Cabe también la posibilidad de que la primitiva imagen del Crucificado fuera sustituida tiempo después_quizás tras el terremoto de Lisboa que tuvo lugar en 1755 y que pudo arruinar el templo mercedario_- por alguna que trajeran desde la provincia de Cádiz en la segunda mitad del siglo XVIII.

Aunque se trata de una imagen con rasgos toscos y algo arcaica, si posee semejanzas con la escuela gaditano-genovesa. Las principales similitudes son los mechones de los cabellos distribuidos en grandes matas, párpados carnosos, nariz recta y afilada, bigote que comienza en las fosas nasales dejando visible el surco labionasal, estrechez del tronco, perizoma pequeño y corona de espinas de cuerda. El aspecto más similar desde el punto de vista morfológico y estilístico es la presencia de llagas, heridas e hilos de sangre en relieves, resaltando el aspecto cruel y realista del momento que se escenifica.

Nuestra hipótesis personal es que el Cristo se encuadre en el siglo XVII y puede atribuirse a una más que posible escuela protogaditana-genovesa, pues a pesar de ser algo arcaica, posee muchas similitudes con imágenes del siglo XVIII encuadradas en dicha escuela. Es una teoría un tanto compleja, pues habría que probar la existencia de escultores italianos en la zona de Cádiz en el siglo XVII, antes del apogeo de esta ciudad cuando se traslada desde Sevilla el Consulado y la Casa de la Contratación.

10 F. J. González García, "Una atribución a la autoría del Santísimo Cristo de Jerusalén y Buen Viaje”, El Dintel 9. (2003), pp. 35-38.

11 J. M. Moreno Arana: "La escultura barroca en las provincias de Cádiz y Huelva", Escultura barroca española. Nuevas lecturas desde los siglos de oro a la sociedad del conocimiento. Escultura barroca andaluza. Vol. II.A. R. Fernández Paradas (coord.), Antequera, 2016, p. 292. 


\section{La devoción al Cristo de Jerusalén y Buen Viaje}

El Santísimo Cristo de Jerusalén y Buen Viaje fue objeto de ardiente devoción por parte de los hombres de la mar y por tantos onubenses que lo veneraban. Es por ello por lo que fueron muchas las personas que, en sus últimas voluntades, mandaban decir misas en su altar y daban por ello una limosna.

El documento más antiguo que prueba la existencia de esta imagen en la primera mitad del siglo XVII es el testamento de Francisco Beltrán, otorgado en 1647, el cual mandaba decir cinco misas rezadas en el altar del Santo Cristo, sin especificar su advocación.

"Iten quiero y es mi voluntad que perpetuamente para siempre xamás se me digan y canten en cada un año, desde el dia de mi fallecimiento en adelante, una memoria de missasresadas en el convento de Descalsos de Ntra. Señora de la Merced desta villa, por sus rreligiosos, de veinte misas rresadas y las sinco restantes en sincoviernes de quaresma en el altar del Santo Cripto". ${ }^{12}$

Cuatro años después, en 1651, otorgó su testamento Catalina Gutiérrez, quien mandara celebrar por su alma dos misas rezadas al Cristo de Jerusalén, siendo este el primer documento que nombra dicha advocación.

\section{"Iten mando se me digan dos misas resadas al Santo Cristo de Jerusalen". ${ }^{13}$}

No descartamos la existencia de una cofradía en la que fuera la principal titular esta imagen pues el médico Diego Fernández Navarro, en su testamento otorgado en 1653, manda dos reales de limosna a la cofradía del Santísimo Sacramento, Ánimas del Purgatorio y Santo Cristo de Jerusalén.

"Iten mando se dé de limosna a la cofradía del Santísimo Sacramento de mi parroquia Ánimas de Purgatorio y Santo Christo de Jerusalem dos reales de limosna a cada una por una vez". ${ }^{14}$

Además, por el testamento de Francisca Prieto, viuda de Díaz Palomino, dictado en el año de 1675, nos llega el primer documento donde se menciona al Crucificado como Santísimo Cristo del Buen Viaje. Francisca mandó tres misas cantadas y seis rezadas a dicha imagen y a la Virgen de la Merced.

12 Huelva, Archivo Municipal Huelva Fondo Díaz Hierro, carpeta 273.1. Huelva, Archivo Histórico Provincial Huelva, testamento de Francisco Beltrán ante Francisco López Machado, otorgado en Huelva el 27 abril de 1647. Caja 4165, fol. 152 vo.

13 Huelva, A.M.H. F.D.H., carpeta 273.2. Huelva, A.H.P.H., testamento Catalina Gutiérrez ante Diego Díaz Lerma, otorgado en Huelva el 24 de marzo de 1651. Caja 4714, fol. 115.

14 Huelva, A.M.H. F.D.H., carpeta 273.2. Huelva, A.H.P.H., testamento del médico Diego Fernández Navarro ante Francisco Díaz Palomino, otorgado en Huelva el 3 de enero de 1653. Caja 4539, fol. 6 vo . 
"Iten mando se digan en el convento de Ntra.Sra. de la Merced al Stmo. Christo del Buen Viaxe y a Ntra. Sra.de la Merced, por sus relixiosos tres misas cantadas y seis resadas, que tengo por devosion el mandar desirla porque asi es mi voluntad". ${ }^{15}$

Por su parte, el alférez Bartolomé Rodríguez de León otorgó su testamento en 1687, y mandó una misa cantada al Cristo del Buen Viaje.

"Iten quiero y es mi voluntad de fundar, como desde luego fundo, otra memoria por mi alma para que desde el dia de mi fallecimiento en adelante se diga en el convento de Ntra. Sra. de la Merced por sus religiosos una misa cantada a su Divina Majestad nuestro Redentor Jesuchristo de Buen Viaje...". ${ }^{16}$

También, en una escritura que se hace ante Diego Díaz Lerma en 1688, se manda una misa cantada en la capilla del Cristo del Buen Viaje todos los viernes.

“...y todos los viernes una misa cantada en la capilla y altar de su divina majestad de Nuestro Señor Jesucristo del Buen Viaxe...". ${ }^{17}$

En 1733 otorgó su última voluntad Ana Manuel, quién mandó dar ocho reales de vellón como limosna por dos misas que se debían de decir en el altar del Cristo del Buen Viaje.

“...ocho reales de vellón limosna de dos misas que an de desir en el altar del Santo Christo del buen Viaje,sitta en el Conventto de nuestra señora de las Mersedesdestta villa, a disposición de cuyo comendador que fuere...". ${ }^{18}$

Más adelante, Catalina de Sera otorgó su testamento en 1751, por el que mandó decir dos misas cantadas al Cristo de la Expiración del convento de la Merced. No nos consta la existencia de otro crucificado en el convento, por lo que no es de extrañar que en el siglo XVIII también pudiera conocerse al devoto Cristo bajo esa advocación.

"Iten mando se digan dos misas cantadas a el Santo Cripto de la Espirazion, que está en el Combento de Ntra. Sra. de las Mercedes de esta villa, las que se aplicarán por

15 Huelva, A.M.H. F.D.H., carpeta 273.2. Huelva, A.H.P.H., testamento Francisca Prieto viuda de Díaz Palomino ante Diego Díaz Lerma, otorgado en Huelva el 18 de junio de 1675. Caja 4189, fol. 222 vo.

16 Huelva, A.M.H. F.D.H., carpeta 273.2. Huelva, A.H.P.H.,testamento del alférez Bartolomé Rodríguez de León ante Diego Díaz Lerma, otorgado en Huelva el 21 de marzo de 1687. Caja 4199, fol. 75.

17 Huelva, A.M.H. F.D.H., carpeta 273.2. Huelva, A.H.P.H., escritura ante Diego Díaz Lerma, otorgado en Huelva el 19 de diciembre de 1688. Caja 4200, fol. 235 vo $^{\circ}$

18 Huelva, A.M.H. F.D.H., carpeta 273.2. Huelva, A.H.P.H., testamento Ana Manuel ante Pedro Martínez Acerado, otorgado en Huelva el 14 de noviembre de 1733. Caja 4747, fol. 71. 
los religiosos de aquella Comunidad, y señalo por la limosna de cada uno sincoreales de vellón". ${ }^{19}$

En 1758 mandó escribir su testamento Micaela Gómez y en él mandaba decir las dos misas de agonía en el altar del Cristo del Buen Viaje, dando por cada una dos reales de vellón en forma de limosna.

"Iten mando se me digan dos misas de Agonía en el Convento de Ntra. Sra. de las Mercedes desta dicha villa, en el Altar del Santo Chripto del Buen Viaje, por el relixioso o relixiosos que fuere voluntad de mis Alvaseas, y señalo por la limosna de cada una dos reales de vellón, que asi es la mía" ${ }^{20}$

Por su parte, Isabel Martin otorgó su testamento en 1760, através del mismo fundó una memoria de dos misas cantadas, una de ellas en el altar del Cristo del Buen Viaje, dando, por ello, una limosna de seis reales de vellón.

"Instituio y fundo desde el día de mi fallecimiento en adelante y para siempre jamás, a cargo del Combento de Ntra. Sra. de las Mercedes desta villa, una memoria perpetua para que en cada un año por mi Anima e intension se me digan dos misas cantadas por los relixiosos del dicho combento, la una el día Domingo de Lázaro en el Altar del Santo Christo del Buen viaje, y la otra el día de Ntra. Sra. de las Mercedes, en su Altar mayor; y señalo por la limosna de cada una seis reales de vellón, la qualsituo otra memoria y señalo sobre diez fanegas para sembrar que tengo mías propias en el campo y término de nuestra dicha villa y sitio que llaman término el cavero de Franco...". ${ }^{21}$

En 1780, también Francisca Álvarez mandó fundar, mediante su testamento, una memoria de dos misas cantadas en el convento, siendo una de ellas en el altar del Cristo del Buen Viaje, dando de limosna ocho reales de vellón por cada una.

"Fundo una memoria de dos misas cantadas que se han de decir en la Yglesia del convento de Ntra. Sra. de la Merced descalzos desta villa por sus religiosos: la primera en el dia y altar de Ntro. Patriarca el Señor San Josef; y la segunda en el Altar del Stmo. Cristo del Buen Viaje en el día de Ascension del Señor, pagando por cada una ocho reales de vellón: cuyas memorias cargo ysitio sobre las enunciadas casas de mi morada en la Vega..., en las que por lo perteneciente al principal de los diez y seis

19 Huelva, A.H.P.H., testamento Catalina de Sera ante Andrés González Valiente, otorgado en Huelva el 4 de junio de 1751. Caja 4253, fol. $117 \mathrm{v}^{\circ}$.

20 Huelva, A.M.H. F.D.H., carpeta 273.2. Huelva, A.H.P.H., testamento Micaela Gómez ante Andrés González Valiente, otorgado en Huelva el 11 de septiembre de 1758. Caja 4259, fol. 220 vo.

21 Huelva, A.M.H. F.D.H., carpeta 273.2. Huelva, A.H.P.H., testamento Isabel Martin ante Andrés González Valiente, otorgado en Huelva el 5 de octubre de 1760. Caja 4261, fol. 218 vo. 
reales correspondientes a las dos misas, cedo, renuncio y traspaso el dominio directo que corresponde a la comunidad de dicho convento...". 22

A partir de la segunda mitad del siglo XVIII algunas personas solicitaron en sus testamentos ser enterradas en el altar del devoto Crucificado. Una de ellas fue María de la Encarnación, quién mandó en 1685 ser sepultada en el altar del Cristo del Buen Viaje.

“...mando que mi cuerpo sea sepultado en la Yglesia del convento de nuestra Señora de la Merced de esta villa, delante del altar del Santo Christo del Buen Viaxe, en la sepultura que alli elixan mis albaseas". ${ }^{23}$

También María de la Encarnación Voloso, mandó en su testamento otorgado en 1691 ser sepultada junto al altar del Cristo.

"Mando que mi cuerpo sea sepultado en la iglesia del Combento de nuestra Señora de la Merced de esta villa, en una de las sepulturas junto a el altar del Santo Christo del Buen Viaxe...". ${ }^{24}$

Más adelante, en 1767, el presbítero Diego Marques Ortiz mandó ser sepultado en la iglesia auxiliar del Santísimo Cristo del Buen Viaje.

“...y que se le dé sepultura siendo en esta esta ciudad, en la iglesia auxiliar del Santísimo Christo del Buenviaje, en la parte que pareciere a mis albaseas". ${ }^{25}$

El Cristo de Jerusalén y Buen Viaje, como es notorio en Huelva, fue una imagen muy devocional, especialmente para los marineros que asociaban esta imagen con la idea de un buen viaje; es por ello por lo que muchos de ellos nombraron a sus embarcaciones con su advocación. Uno de los primeros ejemplos lo tenemos en una escritura ante Antonio Vera del Estoque en 1686.

"Sepan quantos esta carta vieren cómo yo, el alférez Bartolomé Rodríguez, vecino de esta villa de Huelva, dueño y capitán de la Gavarra nombrada el Santo Christo del Buen Viaje, otorgo y comunico que doy todo mi poder cumplido y bastantes quanto de

22 Huelva, A.M.H. F.D.H., carpeta 273.2. Huelva, A.H.P.H., testamento Francisca Álvarez ante Andrés Gómez García, otorgado en Huelva el 22 de abril de 1780. Caja 4600, fol. 24 vo.

23 Huelva, A.M.H. F.D.H., carpeta 273.2. Huelva, A.H.P.H., testamento María de la Encarnación ante Antonio Vera del Estoque, otorgado en Huelva el 10 de agosto de 1685. Caja 4740, fol. 418.

24 Huelva, A.M.H. F.D.H., carpeta 273.2. Huelva, A.H.P.H., testamento María de la Encarnación Voloso ante Antonio de Vera del Estoque, otorgado en Huelva el 26 de junio de 1691. Caja 4743, s/fol.

25 Huelva, Archivo Diocesano Huelva, justicia, Caja 41. Serie 1 Ordinarios, clase 10, números 40-54, años, 1739-1833. Caja 284, 2 junio 1767, fol. 11. Testamento Diego Marques Ortiz, presbítero. 
derechos se requieren a el Padre FranciscoGonzález, religioso de la Sagrada Orden de Predicadores y conventual al presente...".

De1723 tenemos otro ejemplo en una escritura de Miguel Quintero, donde aludía tener un barco nombrado como Santo Cristo del Buen Viaje.

"Cargo en la ría de la de Gibraleón y en barco nombrado Santo Chripto del Buen Viaje y Ntra. Señora de la Concepción, de que es Patrón el otorgante...". ${ }^{26}$

Por otro lado, en 1747 existe una venta de un barco, por parte de Francisco Farías y otros, llamado también Santo Cristo del Buen Viaje, que fue adquirido por el tesorero general del arzobispado hispalense.

"Sépase cómo nos Francisco Farías, Francisco Ramos y José Cordero... otorgamos y cerramos por esta presente carta, quedamos en venta real por uno de heredad al Sr. Franco Amante, tesorero general del SerenísimoSeñor Infante Cardenal Arzobispo de la ciudad de Sevilla y destaDiócesis y procurador general de viveres y utensilios en este reinado, vesino de la misma ciudad, un barco longo obra de codillo de veinteytres codos, nombrado el Santo Cristo del Buen Viaje..., de esta matricula...". ${ }^{27}$

En poder especial de José Bermúdez a Diego Ortiz, otorgado en 1813, sabemos de la curiosa existencia de un barco nombrado igualmente como del Santo Cristo del Buen Viaje y Nuestra Señora de los Dolores. Desconocemos si dicho título se refería a la dolorosa del templo mercedario.

\section{“...barco nombrado el Santo Christo del Buen Viaje y Nuestra Señora de los Do- lores...”. ${ }^{28}$}

Por su parte, en la declaración de propiedad de Francisco de Paula de la Corte a Francisco de Paula Serna, en 1824, se menciona la construcción de una nueva embarcación que llevaría por nombre Virgen de la Paz y el Señor del Buen Viaje.

"Sea notorio como yo Francisco de Paula de la Corte, Maestro carpintero de Rivera de esta matricula, digo: que por cuanto he contratado con Francisco de Paula de la Serna, vecino de San Lucar de Barrameda, la construcción de una barca de bon de 14

26 Huelva, A.M.H. F.D.H., carpeta 273.1. Huelva, A.H.P.H., Miguel Quintero ante Antonio Bautista Monsalve, otorgado en Huelva el 17 de julio de 1723. Caja 4562, fol. 160.

27 Huelva, A.M.H. F.D.H., carpeta 273.1. Huelva, A.H.P.H., venta de barco Francisco Farias y consorte a Francisco Amate ante Francisco Quintano, otorgado en Huelva el 12 de junio de 1747. Caja 4575, fol. 36.

28 Huelva, A.M.H. F.D.H., carpeta 273.1. Huelva, A.H.P.H., poder especial José Bermúdez a Diego Ortiz y otros ante Andrés Guillermo Camacho, otorgado en Huelva el 5 de mayo de 1813. Caja 4297, fol. 128. 
varas de eslora a eslora... señalándole por nombre la Virgen de la Paz y el Señor del Buen Viaje...". ${ }^{29}$

Además de las mencionadas embarcaciones, existe un testamento de Josefa Micaela ante Juan Francisco Gallego de Tovar, otorgado en 1745, donde nombra la existencia de una huerta que también llevaba el nombre de Santo Cristo del Buen Viaje.

"Iten declaramos que los nominados señores Don Pedro Guerrero y Doña Franca MelchoraDominguez, padres legitimosde la referida DoñaJosepha, fundaron un vinculo en la heredad y huerta que llaman el Santo Cripto del Buen Viaje...". 30

\section{DesCripción de la imagen}

El Cristo de Jerusalén y Buen Viaje es una talla en madera de pino policromada, mide 150 centímetros de altura y se trata de una representación de Jesucristo muerto en la cruz. Aparece clavado de manos y pies a una cruz cilíndrica y arbórea por tres clavos.

La imagen tiene la cabeza inclinada hacia abajo y levemente girada hacia su lado derecho. Sobre su cabeza porta tres potencias y una corona de espinas.

Con respecto a los rasgos faciales posee larga nariz afilada, los ojos están cerrados con los párpados muy abultados, los labios aparecen entreabiertos y permiten ver la lengua. El cabello se dispone en ondulados mechones, cayendo un espeso mechón sobre el hombro derecho.

Los brazos y las piernas están rígidos, y las manos se muestran abiertas con los dedos ligeramente flexionados. El pie derecho se monta sobre el izquierdo. El perizoma es de tamaño mediano, se presenta atado con una soga a la cadera, dejando el nudo en la cadera izquierda.

La imagen se caracteriza por el realismo cruento con el que está realizado, destacándose la abundancia de sangre y la representación de heridas y contusiones, llegando a verse los huesos de la espalda. Se puede apreciar una serie de heridas, siendo especialmente destacables la del pómulo izquierdo y las de las dos rodillas. De la frente, costado, manos, rodillas y pies parten unos largos regueros de sangre en relieve.

El Crucificado tiene una doble advocación: por una parte se le denomina Jerusalén y por otra Buen Viaje. Jerusalén fue la ciudad donde se desarrolló la vida, pasión y muerte de Cristo. De hecho, en el antiguo altar del Cristo, a las espaldas de la imagen, se representaba una pintura mural la ciudad santa de Jerusalén.

El título del Buen Viaje nos evoca el tránsito al más allá que sucede después de la muerte. De forma terrenal responde a la despedida humana que se produce cuando los devotos viajeros imploran su protección por tierra, mar o aire. El convento de la Merced estaba situado en una de las puertas de salida de la villa, junto al embarcadero de la ría

29 Huelva, A.H.P.H., declaración de propiedad Francisco de Paula de la Corte a Francisco de Paula Serna ante Francisco Álvarez, otorgado en Huelva el 24 de septiembre de 1824. Caja 4305, fol. 223.

30 Huelva, A.M.H. F.D.H., carpeta 170.18. Huelva, A.H.P.H., Testamento Josefa Micaela ante Juan Francisco Gallego de Tovar, otorgado en Huelva el 9 de abril de 1745. Caja 4752, fol. 32. 

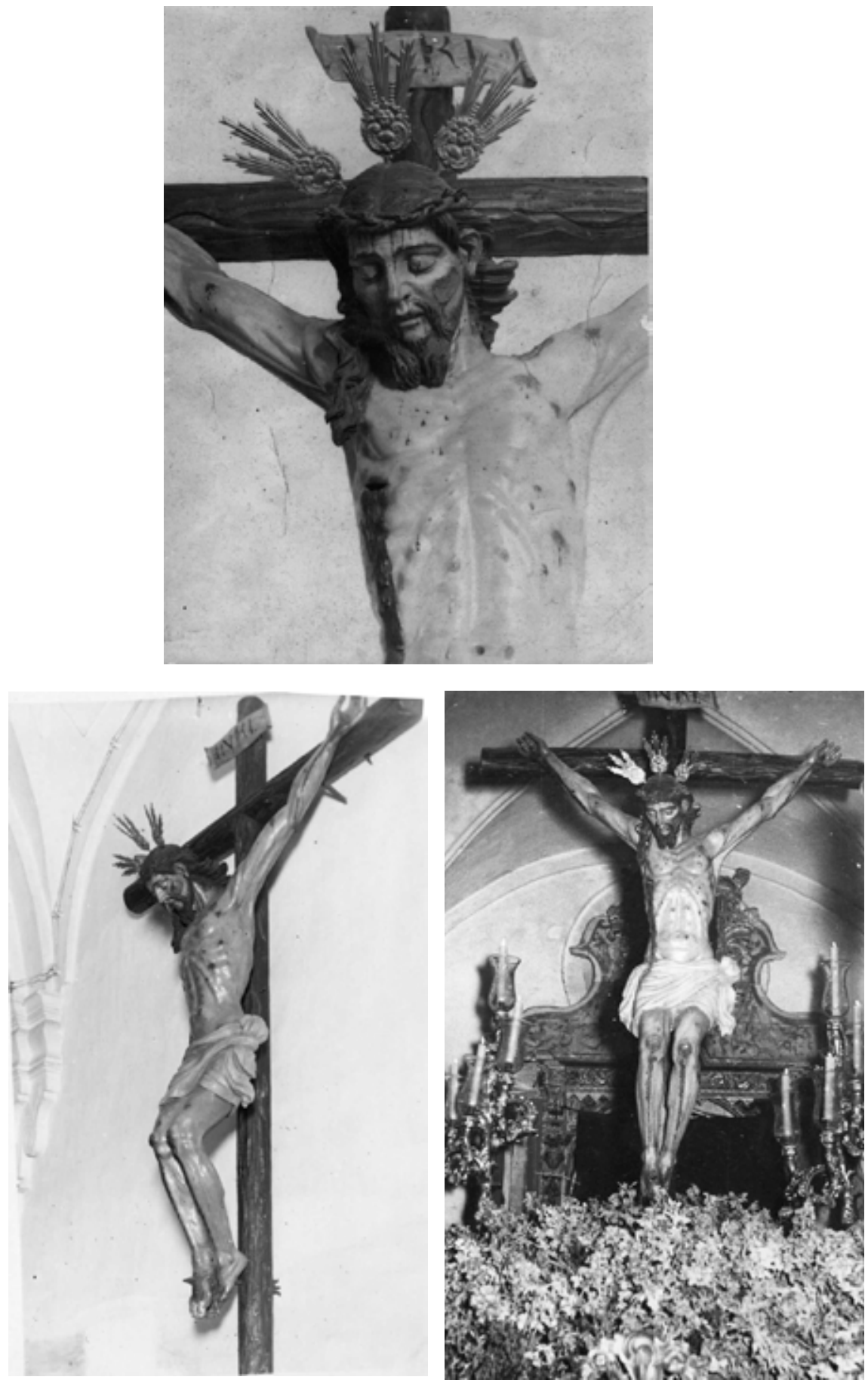

Fotografías del Cristo de Jerusalén y Buen Viaje. Fotos del Fondo Díaz Hierro 
del Odiel; allí se encomendaban a la imagenlos viajeros y los marineros. También su advocación tiene que ver con la misión principal de los frailes mercedarios, la redención de los cristianos cautivos en tierras musulmanas. De ahí que a estos padres mercedarios se les deseara un "buen viaje".

Esta doble advocación ha propiciado que algunos investigadores como José Antonio Fuentes Delgado lleguen a la conclusión, a nuestro parecer errónea, de que las dos advocaciones se debían a dos imágenes distintas; es decir que el Cristo del Buen Viaje, en realidad, se tratara del atado a la Columna. ${ }^{31}$

La imagen se encuentra en el interior del templo catedralicio de la Merced, en un altar ubicado en el lado del Evangelio. El retablo del Crucificado es de estilo barroco, encuadrable dentro de la primera mitad del siglo XVIII. Es de madera tallada, dorada y policromada, de 4,70 metros de alto y 2,30 metros de ancho. Está formado por un banco de un solo cuerpo flanqueado por estípites, con hueco de arco trilobulado que aloja al Cristo, remate semicircular con hornacina central. Presenta decoración de querubines y guirnaldas de flores y frutas.

En el siglo XIX se ubicaba a los pies del Cristo una imagen de una dolorosa, seguramente de pequeñas dimensiones, pues en el inventario de bienes de conventos suprimidos de Huelva, con fecha 31 octubre de 1835 se escribe lo siguiente:

"Otro el Santo Cristo del Buen Viaje en la cruz, y al pie una Sra. mediana del Mayor Dolor, de candelero, con vestido viejo negro, y diadema en oja de lata y de lo mismo las potencias, ara, dos tablillas de Evangelios, dos candeleros en madera en tova, un atril, su velo y cruz". ${ }^{32}$

\section{INCORPORACIÓN A LA HERMANDAD Y AL CORTEJO PROCESIONAL}

El estallido de la Guerra Civil española en Huelva ocasionó múltiples daños a las hermandades penitenciales, destruyéndose sus imágenes titulares — que se veneraban en el interior de los templos- y buena parte de su patrimonio conservado en las iglesias y algunos almacenes.

Esta hermandad fue la única de toda la ciudad de Huelva que no sufrió los estragos de la Guerra Civil. Este hecho se debió a que la iglesia de la Merced se cerró al culto en 1936. La Diputación Provincial, a instigación del director facultativo del Hospital, planeaba el proyecto de destruir la iglesia de la Merced, templo anejo al recinto hospitalario. Por este motivo la iglesia de la Merced no fue asaltada ni saqueada entre el 20 y 21 de julio cuando fueron destruidos todos los templos y conventos de la ciudad, conservándose de ese modo todas las imágenes y patrimonio de la hermandad, así como la iglesia.

31 J. A. Fuentes Delgado, "Sobre las advocaciones de las imágenes titulares de la Hermandad de los Judíos", El Dintel 8, (2002), p. 41.

32 Sevilla, Archivo General Arzobispado Sevilla, sección II. Gobierno. Órdenes religiosas masculinas. Caja 05265, legajo 18, expte. 3. Inventario de bienes de conventos suprimidos de Huelva y San Juan del Puerto. 29 octubre 13 noviembre 1835 . 


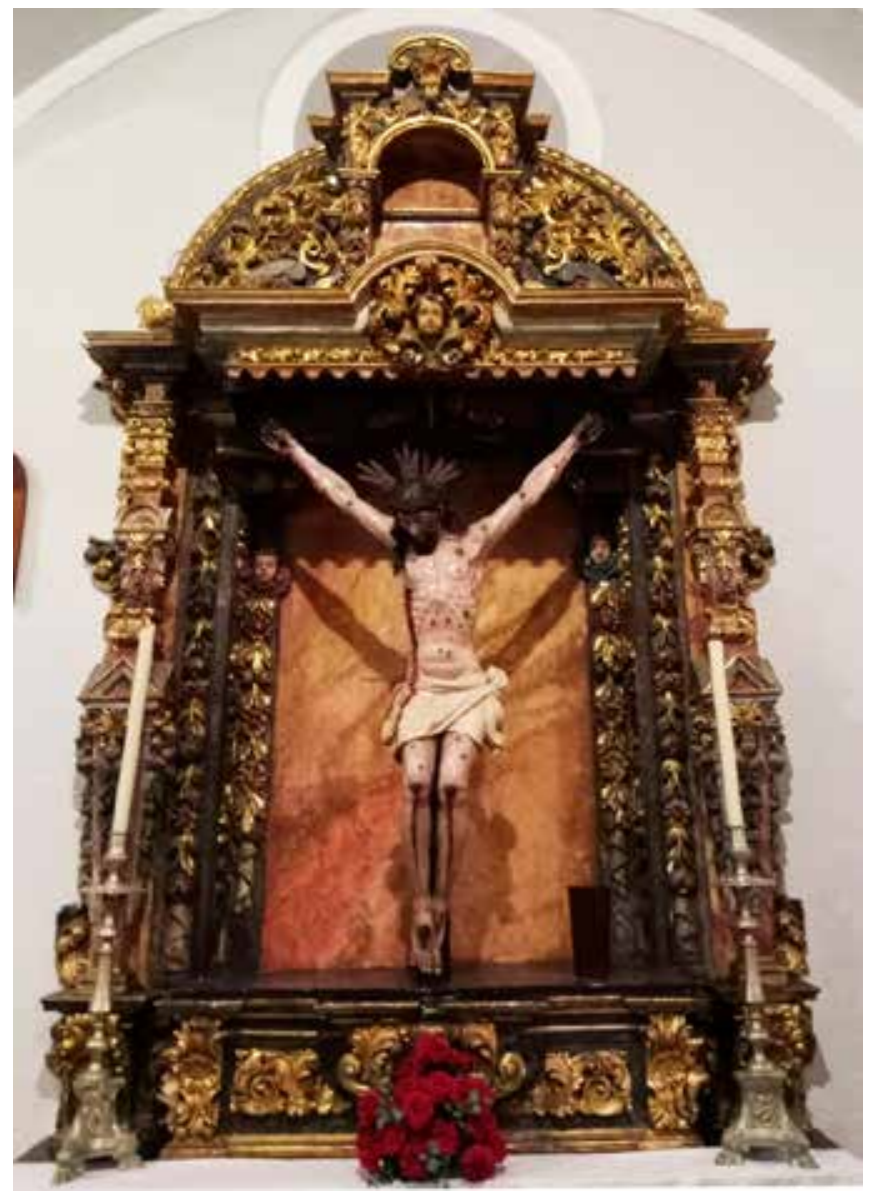

El Cristo de Jerusalén y Buen Viaje en su altar. Archivo personal de la autora

La deplorable situación en la que quedaron las hermandades durante el inicio de la contienda, propició que la imagen del Santísimo Cristo de Jerusalén y Buen Viaje formara parte del desfile procesional de la hermandad de los Judíos en 1937, debido a la estrecha vinculación de la corporación con la Diputación Provincial, hermana mayor honoraria desde 1922, ya que la imagen del Cristo es propiedad del organismo provincial.

El 4 de mayo de 1941 se acordó en sesión ordinaria de la Junta de Gobierno, la incorporación oficial del Crucificado a la cofradía, por la fuerte devoción que despertaba entre los vecinos del barrio. Desde 1944 ocupa el segundo lugar en el cortejo.

Como decíamos, en 1937 y de forma extraordinaria, salió por primera vez el Crucificado dentro del cortejo de la cofradía, siendo acompañado por nazarenos de la hermandad de San Francisco, mientras que en el misterio del Cristo de las Cadenas iban los de Pasión y en el palio de la Virgen de los Dolores los propios de la hermandad. 
El Cristo de Jerusalén y Buen Viaje de la Hermandad de los judíos de Huelva 303

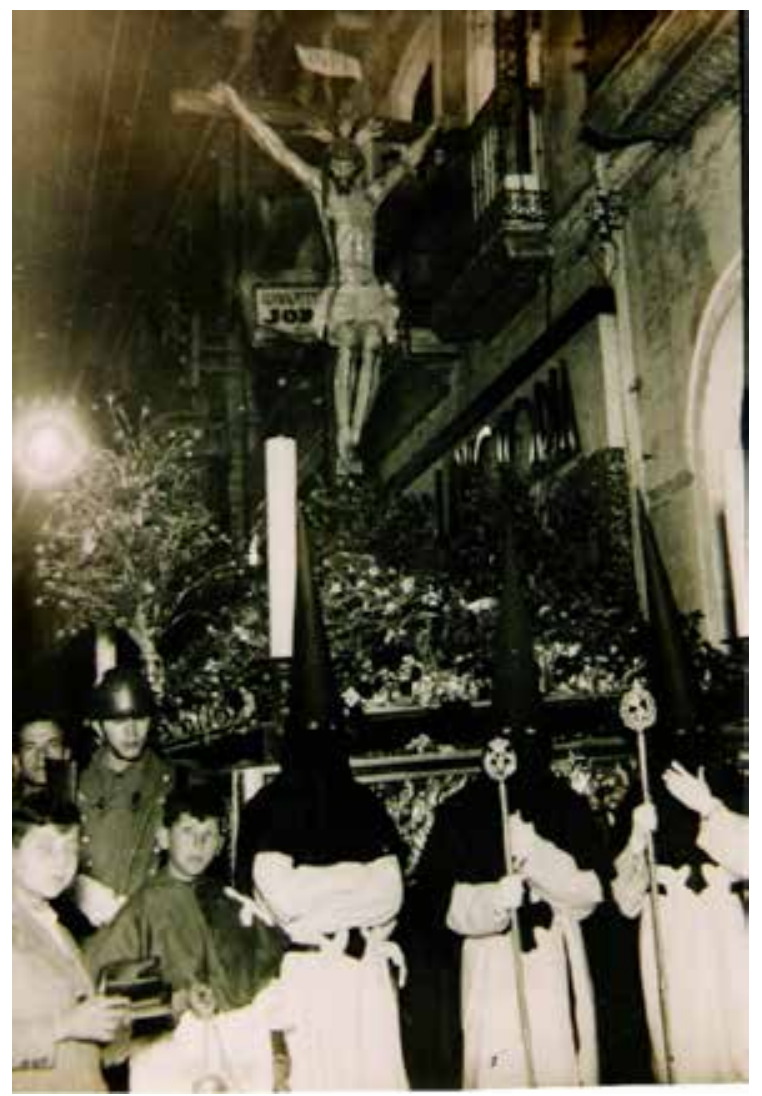

El Cristo de Jerusalén y Buen Viaje en una de sus primeras salidas procesionales.

Foto cedida por la hermandad de los Judíos 
